\title{
Outcome of consistent guideline-based tricuspid management in patients undergoing degenerative mitral regurgitation correction
}

\author{
Gilles D. Dreyfus, MD, PhD, ${ }^{\mathrm{a}, \mathrm{b}, \mathrm{c}}$ Benjamin Essayagh, MD, ${ }^{\mathrm{c}, \mathrm{d}, \mathrm{e}}$ Giovanni Benfari, MD, ${ }^{\mathrm{e}}$
} Filip Dulguerov, MD, ${ }^{\mathrm{c}}$ Shelley Rahman Haley, MD, ${ }^{\mathrm{b}}$ Carine Dommerc, $\mathrm{PhD},{ }^{\mathrm{c}}$ Adelin Albert, $\mathrm{PhD},{ }^{\mathrm{f}}$ and Maurice Enriquez-Sarano, MD $^{\mathrm{e}}$

\begin{abstract}
Objectives: Despite coherent guidelines, management of functional tricuspid regurgitation (FTR) consequences on outcome in the context of degenerative mitral regurgitation (DMR) remains controversial due to lacking series of large magnitude with rigorous application of tricuspid guidelines and strict long-term echocardiographic follow-up. Thus, we aimed at gathering such a cohort to examine outcomes of patients undergoing DMR surgery following tricuspid surgery guidelines.
\end{abstract}

Methods: All consecutive patients with isolated DMR 2005-2015 operated on with baseline FTR assessment and tricuspid annulus diameter measurement were identified. Operative complications, postoperative tricuspid regurgitation incidence, and survival were assessed overall and stratified by guideline-based tricuspid annuloplasty (TA) indication (severe FTR or tricuspid annulus diameter $\geq 40 \mathrm{~mm}$ ).

Results: Among 441 patients with DMR undergoing mitral repair ( $66 \pm 13$ years, $30 \%$ female, ejection fraction $66 \pm 10 \%$, systolic pulmonary artery pressures $39 \pm 12 \mathrm{~mm} \mathrm{Hg})$ followed 6 [3-9] years, patients with TA $(n=234,53 \%)$ had generally similar presentation versus without TA $(n=207,47 \%$; all $P \geq .2)$ except for more atrial fibrillation and larger left ventricle (both $P \geq .0003$ ). Patients with TA showed longer bypass time, more maze procedures (all $P \leq .001$ ), but hospital stay, renal-failure, pacemaker implantation, and operative mortality (overall $0.9 \%$ ) were comparable (all $P \geq .2$ ). Postoperative incidence of moderate/severe FTR ( $\% \%$ at 1 year) became over time greater among patients without TA (5year $8 \%[4 \%-13 \%]$ vs $3 \%[1 \%-11 \%]$ and 10 -year $10 \%[6 \%-16 \%]$ vs $4 \%[1 \%$ $16 \%$ ], $P=.01$ ). Survival (95\% confidence interval) throughout follow-up was $85 \%(77 \%-89 \%)$ at 10 years, with hazard ratio $0.57(0.29-1.10), P=.09$. for patients with TA versus without.

Conclusions: In this large surgical DMR cohort, guideline-based FTR management was safe and effective. While long-term mortality did not reach significance, postoperative incidence of moderate/severe FTR, overall low, was nevertheless greater in patients who did not appear to require TA at surgery and linked to tricuspid annular dimension. Thus, future multicenter prospective cohorts with long-term follow-up are warranted to re-examine thresholds for TA performance and impact on survival. (JTCVS Open 2021;7:125-38)

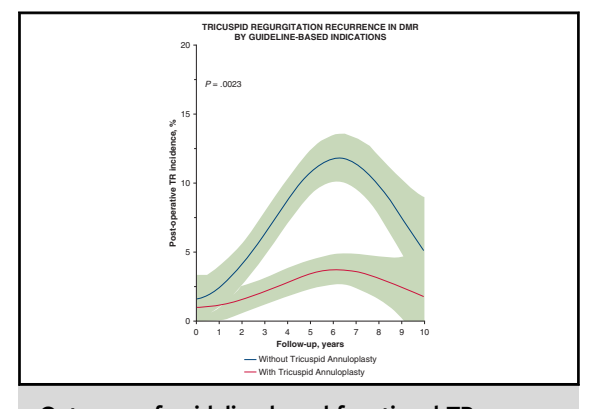

Outcome of guideline-based functional TR surgery in degenerative MR.

\section{CENTRAL MESSAGE}

Guideline-based functional TR management is safe, effective, with lower postoperative incidence of significant functional TR compared to patients without annuloplasty based on annular dimension.

\section{PERSPECTIVE}

The greater rate of postoperative tricuspid regurgitation incidence in patients who did not receive tricuspid annuloplasty, powerfully determined by the tricuspid annular dimension at baseline, underscores the potential for patients with annular diameters $<40 \mathrm{~mm}$ to require annuloplasty and the need for prospective studies to determine the most appropriate threshold for this indication.

See Commentary on page 139.

\footnotetext{
From the ${ }^{\mathrm{a}}$ Department of Cardiac Surgery, Institut Mutualiste Montsouris, Paris, France; ${ }^{b}$ Royal Brompton \& Harefield NHS Foundation Trust, London, United Kingdom; ' ${ }^{\mathrm{C}}$ ardiothoracic Center of Monaco, Monte Carlo, Monaco; ${ }^{\mathrm{d} D e p a r t-}$ ment of Cardiovascular Medicine, Simone Veil Hospital, Cannes, France; ${ }^{\mathrm{e}}$ Department of Cardiovascular Medicine, Mayo Clinic, Rochester, Minn; and ${ }^{\mathrm{f}}$ Department of Biostatistics, University Hospital of Liege, Liege, Belgium.

Received for publication May 15, 2020; accepted for publication July 14, 2021 ; available ahead of print Aug 4, 2021.
}

\footnotetext{
Address for reprints: Gilles D. Dreyfus, MD, PhD, Institut Mutualiste Montsouris, 42 Boulevard Jourdan, Paris, France (E-mail: gillesdreyfus1@gmail.com). 2666-2736

Copyright (C) 2021 The Authors. Published by Elsevier Inc. on behalf of The American Association for Thoracic Surgery. This is an open access article under the CC BY-NC-ND license (http://creativecommons.org/licenses/by-nc-nd/4.0/). https://doi.org/10.1016/j.xjon.2021.07.010
} 


$$
\begin{aligned}
& \text { Abbreviations and Acronyms } \\
& \mathrm{AFib}=\text { atrial fibrillation } \\
& \mathrm{CI}=\text { confidence interval } \\
& \text { DMR = degenerative mitral regurgitation } \\
& \text { FTR = functional tricuspid regurgitation } \\
& \text { GLMM }=\text { generalized linear mixed model } \\
& \mathrm{LV} \quad=\text { left ventricle } \\
& \text { MR = mitral regurgitation } \\
& \text { NYHA }=\text { New York Heart Association } \\
& \mathrm{OR}=\text { odds ratio } \\
& \text { TA }=\text { tricuspid annuloplasty } \\
& \text { TAd = tricuspid annulus diameter } \\
& \text { TR }=\text { tricuspid regurgitation }
\end{aligned}
$$

Functional tricuspid regurgitation (FTR) associated with mitral valve disease is the most frequent cause of tricuspid regurgitation (TR) ${ }^{1}$ and most often occurs in the context of degenerative mitral regurgitation (DMR). ${ }^{2}$ FTR has had a benign reputation, yielding the concept that complete tricuspid valvulectomy may be well tolerated. Such resulted in the classic recommendation to ignore it during mitral surgery based on its predicted postoperative improvement and on the primacy of the mitral disease. However, over time, these concepts have evolved and, in particular, the serious impact of FTR on the outcome of patients affected by DMR has been recognized as quite poor, ${ }^{3}$ strongly related to the severity of FTR, even moderate, and independently of any baseline characteristics. ${ }^{4}$ Furthermore, surgical series have emphasized the relative frequency of residual/ recurrent FTR after mitral surgery, ${ }^{5,6}$ depending on a variety of characteristics, particularly tricuspid annular enlargement. Also, reoperations for severe postoperative FTR have long been shown to carry high mortality and frequent recurrences. $^{7}$

Hence, a more proactive approach to the treatment and prevention of FTR during surgical repair of DMR has been suggested, ${ }^{6}$ which may be crucial as DMR is likely to allow highly successful ${ }^{8}$ and early repair. ${ }^{9}$ While functional improvements have been reported in series with proactive use of tricuspid repair, ${ }^{10-12}$ no clinical trial of FTR proactive treatment/prevention has been yet completed, and the proactive approach to FTR repair has been highly controversial, ${ }^{13,14}$ reflected by widely different rates of tricuspid repair performed during mitral repair. ${ }^{10}$ This controversy, pushed by strong surgical voices, has been exacerbated by frequently incomplete echocardiographic follow-up ${ }^{13}$ and has led to different adoption timing between US and European guidelines, ${ }^{15,16}$ with incomplete guideline adoption and severe FTR undertreatment in DMR. $^{4}$

In considering tricuspid valve management in DMR, knowledge of the outcomes following the proactive tricuspid guideline application is paramount until results of clinical trials become available. Thus, we aimed to examine for the first-time clinical and echocardiographic outcomes of a large cohort of patients undergoing DMR surgery with rigorous application of tricuspid guidelines and strict long-term echocardiographic follow-up.

\section{METHODS}

All consecutive patients with isolated DMR operated on by the surgical team in 2 separate institutions (Royal Brompton and Harefield NHS Foundation Trust, United Kingdom; Cardio Thoracic Centre of Monaco) between January 2005 and December 2015 (2005-2009, United Kingdom; 2010-2015, Monaco) were included. Exclusion criteria were the absence of research authorization per European law, presence of pacemakerdefibrillator, organic TR, moderate or greater aortic valve disease, mitral stenosis, rheumatic or functional mitral regurgitation (MR) (per guidelines), ${ }^{16,17}$ any previous valve surgery, any other myocardial/pericardial/ congenital heart disease including triple-vessel coronary disease, and the absence of tricuspid annulus measurement on transthoracic echocardiography. The study was approved by the Ethic committee of the Royal Brompton and Harefield NHS Foundation Trust, London, United Kingdom, in March 2017 following a retrospective analysis of anonymous data from patients operated in between January 2005 and December 2009, as well as from the Cardiothoracic Center of Monaco in March 2017 for patients in between January 2010 until December 2015. The institutional review boards of these institutions waived the need for patient written informed consent.

\section{Echocardiographic Evaluation}

Echocardiography performed by experienced in-hospital sonographers with special interest in mitral and tricuspid valve pathology included comprehensive measures and grading using standardized echocardiographic phrases. Those were stored immediately in an image and data repository and retrieve without alteration or reinterpretation for the study. Degenerative mitral valve disease was defined as excess leaflet motion (type II of Carpentier's classification) resulting from chordal elongation or chordal rupture ${ }^{18}$ and DMR severity assessed by integrative grading with quantitative assessment as often as possible. ${ }^{19}$ FTR was diagnosed by comprehensive tricuspid valve examination excluding structural abnormalities and graded using standardized phrases according to American Society of Echocardiography guidelines as absent, mild, moderate, and severe. ${ }^{17}$ Systolic pulmonary artery pressure was calculated using continuous-wave Doppler FTR velocity and right atrial pressure estimated using inferior vena cava imaging. Left atrial volume and left ventricle size/ function were systematically defined according to American Society of Echocardiography guidelines. ${ }^{20}$

Per guidelines, ${ }^{15,16}$ the indication for tricuspid annuloplasty (TA) was based on concomitant severe FTR, or preoperative tricuspid annulus diameter (TAd) enlargement associated with DMR regardless of FTR severity, measured for all patients by transthoracic (4-chamber view) or transesophageal echocardiography in end-diastole before surgery. TAd assessment was always performed before surgery, irrespectively of FTR grading, and led TA decision in the absence of severe FTR. Intraoperative echocardiographic findings did not indicate concomitant FTR surgery. According to those criteria, the cohort was divided in 2 groups: patients with TA (severe TAd $\geq 40 \mathrm{~mm}$ ) and patients without TA (TAd $<40 \mathrm{~mm}$ ). 


\section{Operative Techniques}

Cardiac surgeries were performed under normothermia, and cardiopulmonary bypass was established in between the ascending aorta and bicaval cannulation. Myocardial protection was achieved with cold crystalloid (St Thomas Formula). TAd enlargement was treated with a rigid ring (Carpentier-Edwards, Edwards Lifesciences, Irvine, Calif). Maze procedure by left atrial complete ablation protocol (box and left atrial appendage base lesion, left atrial appendage resection, and inferior/mitral annulus line) was performed unchanged over the study period, and indicated upon paroxysmal atrial fibrillation (AFib) or recent permanent $\mathrm{AFib}(\leq 1$ year), using a radiofrequency bipolar clamp (AtriCure's Isolator Synergy Ablation System; AtriCure, Mason, Ohio). As a first step, the mitral valve was approached through the interatrial groove and repaired by a variety of techniques, specifically adapted to the lesions. Ring annuloplasty was used in all cases. As a second step, the right atrium was opened vertically in parallel to the atrioventricular groove. The size of the tricuspid ring was measured accordingly to the unfolded anterior leaflet. The TA ring (Carpentier-Edwards, Edwards Lifesciences) was inserted using a series of 3-0 ETHIBOND mattress sutures (Videos 1 and 2). The surgical technique remained unchanged over the study period.

\section{Clinical Evaluation}

Patients' demographic and clinical data, including New York Heart Association (NYHA) functional classification, were recorded at baseline and during in-hospital stay by patients' personal physicians in charge and electronically retrieved from medical files without alteration. AFib before/at diagnosis relied on ECG or clinical notes for history of proven AFib. Surgical data included bypass time, crossclamping time, coronary artery bypass graft, maze procedure, and size of the semi-rigid ring for patients with TA. Postoperative renal failure (defined as creatinine level $\geq 200 \mathrm{mg} / \mathrm{dL}$ ), use of intra-aortic balloon pump, inotropic support, implantation of pacemaker before discharge, occurrence of thromboembolic event, reoperation, and length of in-hospital stay were recorded during in-hospital stay by the physician in charge and electronically retrieved from medical files without alteration. After hospital discharge, patients were seen at out-patient clinic within 3 months and then followed up annually.

\section{Follow-up Data}

Primary outcome of interest was postoperative cumulative incidence of moderate/severe FTR based on standardized postoperative yearly echocardiographic assessment. Secondary end point was overall survival. Recurrent MR was defined as moderate or greater postoperative MR. ${ }^{16,19}$ Postoperative TR related to pacemaker implantation was defined based on anatomical criteria (leaflet restriction). Death occurrence and dates

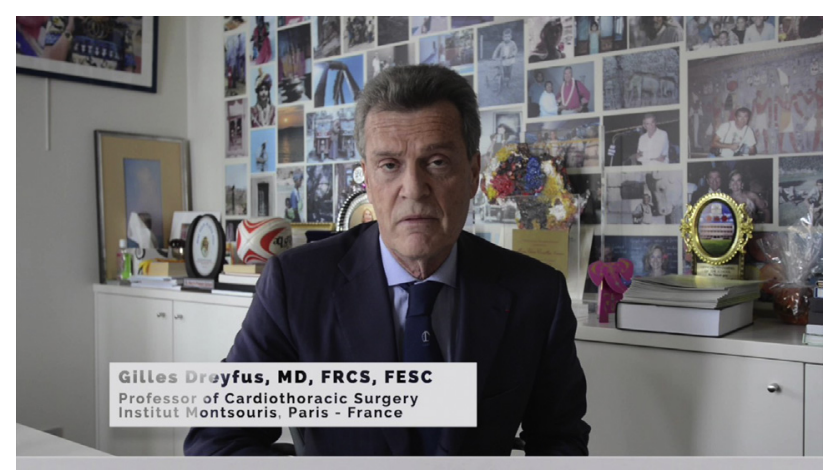

VIDEO 1. Presentation of the importance and relevance of the paper. Video available at: https://www.jtcvs.org/article/S2666-2736(21)00195-9/ fulltext.

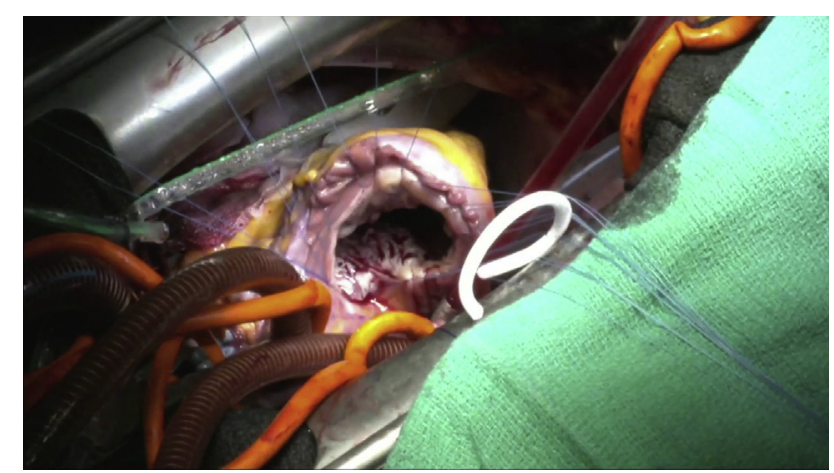

VIDEO 2. Tricuspid annuloplasty operative procedure in the context of degenerative mitral regurgitation surgery. Video available at: https:// www.jtcvs.org/article/S2666-2736(21)00195-9/fulltext.

obtained for all were recorded based on medical record, yearly follow-up in out-patient clinic, or phone calls for patients not responding to follow-up echocardiographic evaluation, and patients alive were censored on December 31, 2017.

\section{Statistical Analysis}

Continuous data expressed as mean \pm standard deviation or median [interquartile-range] were compared using analysis of variance or the Wilcoxon test. For qualitative data, proportions were compared by the classical $\chi^{2}$ test or Fisher exact test as appropriate. Logistic regression and the odds ratio (OR) were used to assess the relationship between a binary outcome and a set of covariates. Odds ratios were associated with a $95 \%$ confident interval ( $95 \% \mathrm{CI})$, and adjustable variables were age, sex, DMR, and FTR severity. Time-to-event variables were displayed using Kaplan-Meier survival curves and analyzed with respect to covariates by the Cox proportional hazards regression model. Results were expressed by the hazard ratio with $95 \%$ CI. The proportional hazards assumption in Cox regression was tested using Schoenfeld residuals, and the result was not significant $(P=.20)$. The cumulative incidence of moderate/severe FTR was estimated by the competing risk model and assessed with respect to TA and other covariates. Postoperative echocardiographic longitudinal data were analyzed by the generalized linear mixed model (GLMM) in which the covariates were time (both linear and quadratic effects), TA, and interaction between TA and time. Results were expressed as regression coefficients with their standard error. All statistical calculations were performed with SAS (version 9.4) software package.

\section{RESULTS \\ Baseline Characteristics}

Baseline characteristics are displayed in Table 1. Of the 441 patients with DMR constitutive of the final cohort, $234(53 \%)$ underwent TA concomitant to mitral valve surgery and $207(47 \%)$ did not. Only few differences were noted among TA subsets, and particularly no difference in NYHA functional class, age at time of surgery, or body surface area (all $P \geq .2$ ). Patients who underwent TA had enlarged left ventricle (LV) end-diastolic diameter, more frequent AFib, and moderate/severe FTR than patients without TA (all $P \leq .009$ ). No severe TR was noted among patients with TAd $<40 \mathrm{~mm}$ (vs 4 in patients with TAd $\geq 40 \mathrm{~mm}$, Table 1). AFib was strongly associated 
TABLE 1. Preoperative characteristics of patients according to tricuspid annuloplasty

\begin{tabular}{|c|c|c|c|}
\hline & Patients without TA $($ TAd $<40 \mathrm{~mm}), \mathrm{n}=\mathbf{2 0 7}$ & Patients with TA $(\operatorname{Tad} \geq 40 \mathrm{~mm}) \mathrm{n}=\mathbf{2 3 4}$ & $P$ value \\
\hline \multicolumn{4}{|l|}{ Clinical characteristics* } \\
\hline Cohort, n $(\%)$ & & & .9 \\
\hline United Kingdom & $90(43)$ & $104(44)$ & \\
\hline Monaco & $117(57)$ & $130(56)$ & \\
\hline Age, y & $67 \pm 14$ & $65 \pm 12$ & .2 \\
\hline Female, n (\%) & $141(68)$ & $168(72)$ & .4 \\
\hline $\mathrm{BSA}, \mathrm{m}^{2}$ & $1.80 \pm 0.2$ & $1.84 \pm 0.2$ & .4 \\
\hline AFib, n (\%) & $48(23)$ & $92(39)$ & .0003 \\
\hline NYHA III-IV, n (\%) & $74(36)$ & $87(37)$ & .8 \\
\hline \multicolumn{4}{|c|}{ Echocardiographic variables } \\
\hline LV-EF, \% & $66 \pm 9$ & $65 \pm 10$ & .2 \\
\hline LV-EDD, mm & $56 \pm 7$ & $59 \pm 8$ & .0008 \\
\hline LV-ESD, mm & $36 \pm 6$ & $37 \pm 7$ & .2 \\
\hline $\mathrm{LAVI}, \mathrm{mL} / \mathrm{m}^{2}$ & $83 \pm 34$ & $82 \pm 36$ & .7 \\
\hline sPAP, mm Hg & $39 \pm 12$ & $40 \pm 11$ & .2 \\
\hline Severe MR, n (\%) & $200(97)$ & $232(99)$ & .2 \\
\hline TAd, mm & $36 \pm 2$ & $43 \pm 2$ & $<.0001$ \\
\hline FTR grade, n (\%) & & & $<.0001$ \\
\hline No/mild & $187(90)$ & $166(71)$ & \\
\hline Moderate & $20(10)$ & $64(27)$ & \\
\hline Severe & $0(0)$ & $4(2)$ & \\
\hline
\end{tabular}

TA, Tricuspid annuloplasty; TAd, tricuspid annulus diameter; BSA, body surface-area; AFib, atrial fibrillation; NYHA, New York Heart Association functional classification; $L V$, left ventricle; $E F$, ejection fraction; $E D D$, end-diastolic diameter; $E S D$, end-systolic diameter; $L A V I$, left atrial volume index; $s P A P$, systolic pulmonary artery pressure; $M R$, mitral regurgitation; FTR, functional tricuspid regurgitation. *No missing data.

with FTR grade, present in $27 \%(\mathrm{n}=95)$ of cases with no/mild FTR, $50 \%(n=42)$ of cases with moderate FTR, and $75 \%(\mathrm{n}=3)$ of cases with severe FTR $(P<.0001)$. Logistic regression showed that AFib was independently associated with concomitant TA when adjusting for age, sex, DMR, and FTR severity (OR, 2.55; $95 \%$ CI, 1.64-3.97, $P<.0001)$.

\section{Surgical Procedure}

In the group receiving TA, the size of semi-rigid annuloplasty ring was $32 \pm 2 \mathrm{~mm}$ (extremes $28-36 \mathrm{~mm}$, Table 2 , top panel). Both bypass and crossclamping times were longer in patients with TA $(P \leq .001)$. Fewer cases of coronary artery bypass graft and more maze procedures were performed in patients with TA $(P=.0002)$, in relation to

TABLE 2. Surgical characteristics, in-hospital complications, and long-term outcomes

\begin{tabular}{|c|c|c|c|}
\hline & $\begin{array}{c}\text { Patients without TA } \\
\text { TAd }<\mathbf{4 0} \mathbf{~ m m}, \mathbf{n}=\mathbf{2 0 7}\end{array}$ & $\begin{array}{c}\text { Patients with TA } \\
\text { TAd } \geq \mathbf{4 0} \mathbf{~ m m}, \mathbf{n}=\mathbf{2 3 4}\end{array}$ & $P$ value \\
\hline \multicolumn{4}{|l|}{ Surgery } \\
\hline TA ring size, mm & N/A & $32 \pm 2$ & N/A \\
\hline Bypass time, min & $125 \pm 50$ & $138 \pm 36$ & .001 \\
\hline Crossclamp time, $\min$ & $99 \pm 38$ & $113 \pm 30$ & $<.0001$ \\
\hline CABG, n (\%) & $38(18)$ & $16(7)$ & .0002 \\
\hline Maze, n (\%) & $20(10)$ & $53(23)$ & .0002 \\
\hline \multicolumn{4}{|l|}{ Hospitalization } \\
\hline Length of stay, d & $11[9-12]$ & $10[10-12]$ & .2 \\
\hline IABP, n (\%) & $4(2)$ & $0(0)$ & .05 \\
\hline Renal insufficiency, n (\%) & $4(2)$ & $5(2)$ & .9 \\
\hline PM before discharge, $\mathrm{n}(\%)$ & $25(12)$ & $22(9)$ & .4 \\
\hline Inotropes drugs, $\mathrm{n}(\%)$ & $44(21)$ & $51(22)$ & .9 \\
\hline In-hospital death, n (\%) & $2(1)$ & $2(1)$ & .9 \\
\hline \multicolumn{4}{|l|}{ Long-term outcomes } \\
\hline Follow-up, y & $5[2-7]$ & $6[3-7]$ & .1 \\
\hline Death, postdischarge, $\mathrm{n}(\%)$ & $19(9)$ & $13(6)$ & .1 \\
\hline
\end{tabular}

$T A$, Tricuspid annuloplasty; $T A d$, tricuspid annulus diameter; $N / A$, not applicable; $C A B G$, coronary artery bypass graft; $I A B P$, intra-aortic balloon pump; $P M$, pacemaker. 
greater AFib occurrence. A second crossclamp time was completed for significant residual MR detected by transesophageal echocardiography in 11 patients. Ultimately successful mitral valve repair (no or mild postoperative MR) was achieved in all.

After surgery, median in-hospital stay was similar in both groups as well as proportions of patients with renal failure ( $2 \%$ of entire cohort), requiring postprocedure pacemaker implantation or inotropic support (Table 2, middle panel). There were 4 in-hospital deaths ( 2 in each group, $P=.9$ ) due to low cardiac output, yielding an early mortality of $0.9 \%$. No stroke, no systolic anterior motion of the mitral valve after repair, no hemolysis, and no infective endocarditis were reported in either group.

\section{Incidence of TR After Mitral Valve Surgery}

Median follow-up was 6 [3-9] years, with no difference among TA groups $(P=.1$, Table 2 , bottom panel). Overall, 21 patients (15 cases without TA and 6 with TA) were diagnosed with moderate or greater FTR after DMR surgical correction (Table 3), corresponding to a low incidence of $7 \pm 1 \%$ at 10 years. Three patients with TA developed severe TR lately ( $\geq 6$ years postsurgery for all), all related to pacemaker implantations impinging on the tricuspid valve leaflets. Preoperative AFib was associated with FTR recurrence in patients without concomitant TA based on guidelines indication (adjusted OR, 3.01; 95\% CI, 1.01-9.28, $P=.049$ ) versus patients with TA (adjusted OR, $1.59 ; 95 \%$ CI, 0.22-11.44, $P=.7$ ).

The cumulative incidence of moderate/severe FTR derived by competing risk analysis differed significantly between patients without TA and with TA $(P=.01$; Figure 1$)$. While 1-year incidence of moderate or greater FTR was $0 \%$ in both groups, it increased to $8 \%$ [4\%-13\%] in patients without TA versus 3\% [1\%-11\%] in patients with TA at 5 years. At 10 years, cumulative incidence reached $10 \%$ [6\%-16\%] in patients without TA versus $4 \%$ [1\%-16\%]

TABLE 3. FTR grade at baseline and during follow-up in patients, stratified by tricuspid annuloplasty

\begin{tabular}{clcc}
\hline & \multicolumn{1}{c}{ FTR grade } & Preoperative & $\begin{array}{c}\text { During } \\
\text { follow-up }\end{array}$ \\
\hline $\begin{array}{c}\text { Patients without TA } \\
(\text { TAd }<40 \mathrm{~mm})\end{array}$ & No/mild FTR, n (\%) & $187(90)$ & $192(93)$ \\
& Moderate FTR, n (\%) & $20(10)$ & $15(7)$ \\
& Severe FTR, n (\%) & $0(0)$ & $0(0)$ \\
\hline $\begin{array}{c}\text { Patients with TA } \\
(\text { TAd } \geq 40 \mathrm{~mm})\end{array}$ & No/mild FTR, n (\%) & $166(71)$ & $228(98)$ \\
& Moderate FTR, n (\%) & $64(27)$ & $6(3)$ \\
& Severe FTR, n (\%) & $4(2)$ & $0(0)$ \\
\hline
\end{tabular}

FTR, Functional tricuspid regurgitation; TA, tricuspid annuloplasty; TAd, tricuspid annulus diameter. in patients with TA $(P=.01)$. No reoperation for moderate/severe FTR was indicated in either group. When we analyzed the longitudinal measurements of FTR (none/minor vs moderate/severe) by GLMM analysis, the probability of moderate/severe FTR could be graphed over time in both patient groups (without or with TA), as displayed in Figure 2. GLMM analysis evidenced significant linear $(P=.0015)$ and quadratic $(P=.0062)$ effects of time and a significant difference between the 2 TA groups $(P=.0023)$.

\section{Long-Term Mortality and Complications}

At long-term follow-up, 32 deaths were recorded, 13 among patients with TA versus 19 without TA $(P=.1)$. Survival curves stratified by TA are displayed in Figure 3, with overall survival $85 \%[77 \%-89 \%]$ at 10 years. A trend for greater survival in patients with TA was observed without reaching statistical significance (hazard ratio, 0.57 [0.29$1.10], P=.09$ ). Indeed, overall survival was $98 \pm[96 \%$ $99 \%]$ at 1 year, $95 \pm[91 \%-97 \%]$ at 5 years, and $88 \pm[80 \%-93 \%]$ at 10 years in patients with TA compared with $98 \pm[94 \%-99 \%], 94 \pm[89 \%-97 \%]$, and $79 \pm[66 \%$ $88 \%$ ], respectively, in patients without TA. Of note, the proportion of patients affected by thromboembolic events was similar in both groups $(P=.1)$, and only 7 patients were reoperated for recurrent MR.

\section{Echocardiographic and Clinical Follow-up Assessment}

Postoperative echocardiographic longitudinal data (Table E1) showed decreased LV ejection fraction in both groups during the first year after surgery but significantly increased afterwards in patients without TA while remaining stable in patients with TA $(P=.03)$. Evolution of LV end-diastolic diameter and LV end-systolic diameter were similar with marked linear and quadratic time effect (both $P<.0001$ ) with postoperative values (steadily greater in patients with TA from the preoperative phase throughout), and decreasing in parallel in both groups $(P \geq .2)$. Mean values remained $<60 \mathrm{~mm}$ for $\mathrm{LV}$ end-diastolic diameter and $<40 \mathrm{~mm}$ for LV end-systolic diameter. Similarly, leftatrial volume-index values were slightly greater in TA patients throughout the follow-up period but leveled off in patients with TA, whereas they continued to decrease in patients without TA $(P \leq .045)$. Evolution of systolic pulmonary artery pressure was curvilinear though similar in both groups. Also, left atrial/LV gradient (not available preoperatively) did not significantly change over time. Proportion of patients with NYHA III/IV decreased over time similarly in both groups (all $P \geq .2$ ).

\section{DISCUSSION}

Our consecutive series of patients undergoing surgery for DMR with uniform guideline-based tricuspid management 


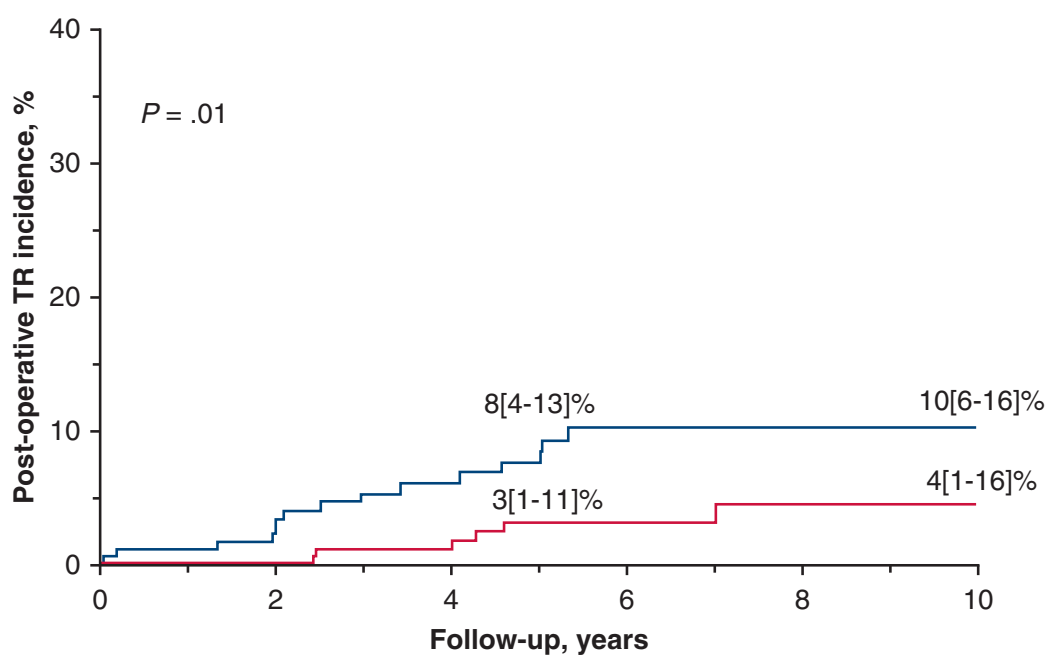

\begin{tabular}{llll}
\multicolumn{2}{c}{ Patients at risk } & & \\
- Without TA 207 & 169 & 128 \\
- With TA 234 & 203 & 162
\end{tabular}

$\begin{array}{ccc}78 & 31 & 10 \\ 117 & 49 & 20\end{array}$

FIGURE 1. Impact of tricuspid annuloplasty on postoperative functional TR. Postmitral valve surgery cumulative incidence of moderate/severe functional TR in patients with tricuspid annuloplasty (blue curve) and without tricuspid annuloplasty (red curve). Note the marked separation between curves, maintained throughout the entire follow-up period. Cumulative incidence of postoperative functional TR rates at 5 and 10 years are given with $95 \%$ [CI]. TA, Tricuspid annuloplasty; $T R$, functional tricuspid regurgitation.

involving TA performed in patients with severe FTR preoperatively (class I) or any degree of FTR and tricuspid annulus dimension $\geq 40 \mathrm{~mm}$ (Class IIa) demonstrates that this approach is safe and effective. Foremost, with such guideline-based consistent tricuspid management the incidence-rate of postoperative moderate or severe FTR remains very low long term after surgery. Furthermore, this result is achieved with no increase in hospital mortality or morbidity in patients requiring TA. However, patients in whom there was no indication for TA according to these guidelines, despite presenting at baseline with a lower tricuspid annular dimension, incurred greater postoperative FTR incidence than those requiring TA, emphasizing the long-term protective impact of annuloplasty ring implantation (Figure 4). This greater rate, powerfully determined by the tricuspid annular dimension at baseline, underscores the

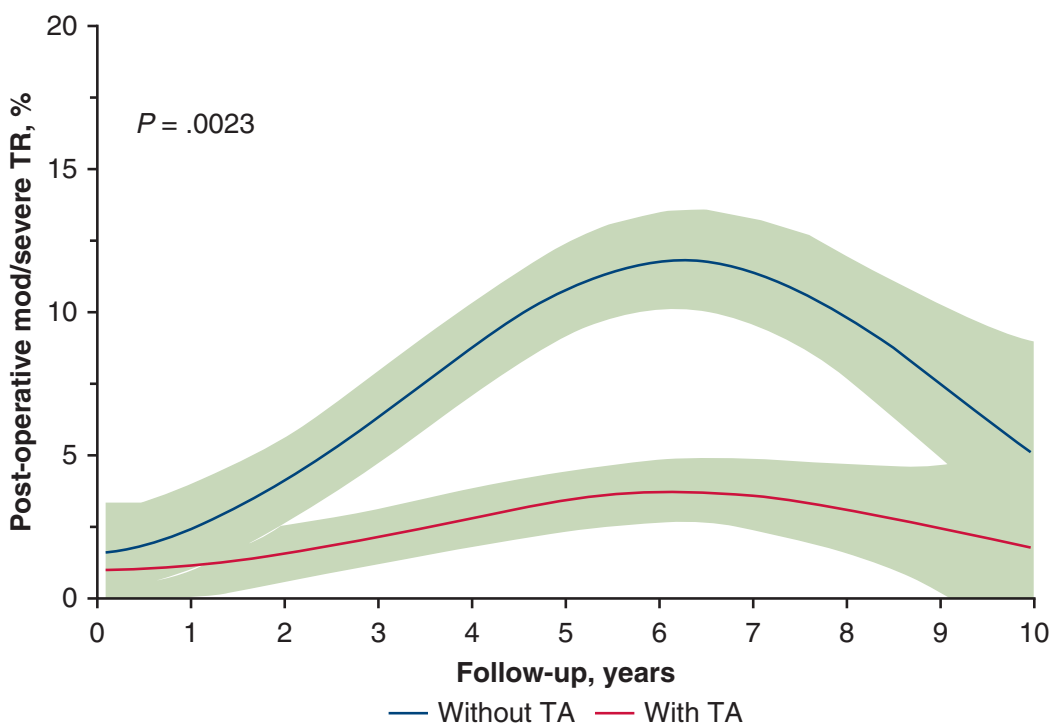

FIGURE 2. Probability of postoperative functional TR according to TA performance. Curves of GLMM probability over time to develop postoperative moderate/severe functional TR according to concomitant TA. Note that the curve is almost flat in patients with TA (blue curve) and goes up and then descends in patients without TA (red curve). Confidence bounds were obtained by bootstrapping. TA, Tricuspid annuloplasty; $T R$, tricuspid regurgitation. 


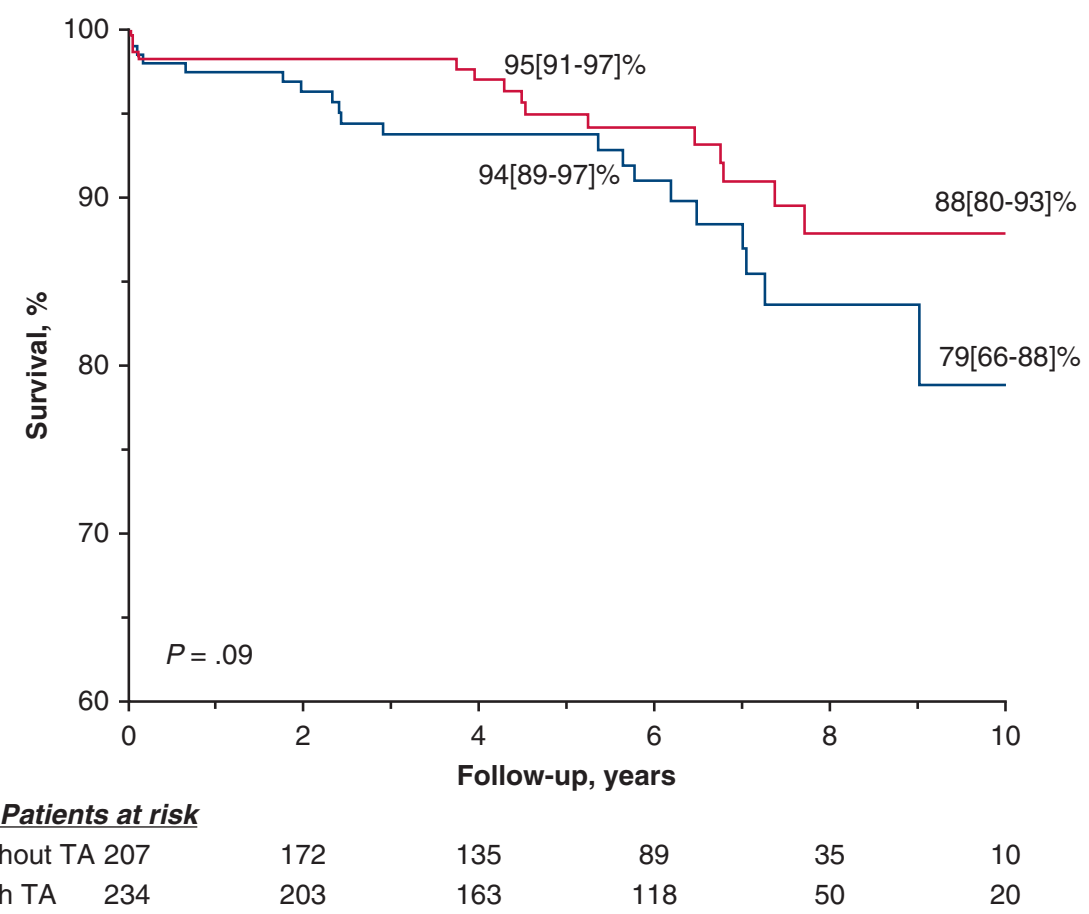

FIGURE 3. Survival stratified by TA. The figure displays Kaplan-Meier curves for patients with (blue curve) TA and without (red curve) TA in the overall cohort. Survival rates at 5 and 10 years are given with $95 \%$ [CI]. TA, Tricuspid annuloplasty.

potential for patients with annular diameters $<40 \mathrm{~mm}$ to ultimately develop TR and the need for prospective studies to determine the most appropriate threshold for TA indication. Conversely, in patients postannuloplasty, incidence of TR was extremely low, unrelated to the tricuspid annulus diameter and often due to pacemaker implantation. Finally, the link between TR and MR recurrence emphasizes the importance of the quality of the mitral repair for postoperative outcome. While mortality tended to be lower post TA, the difference did not reach statistical significance, emphasizing the importance of future multicenter prospective cohorts. Thus, our consistent experience with proactive tricuspid repair during DMR repair considerably increased the number of tricuspid repairs performed $(n=234)$ versus a policy just based on the presence of severe TR $(n=4)$ but did not increase the risks incurred by patients and reduced the rates of recurrent TR long term after surgery.

\section{Annular Dilatation and TR}

The tricuspid annulus is a relatively tenuous structure, which has a high margin of physiologic variability, even with the normal respiratory cycle. ${ }^{21}$ Another markedly plastic structure, the right ventricle, displays also considerable physiologic variability in dimensions and shape,${ }^{21}$ affecting the tricuspid valve through the chordae exerting variable traction on the leaflets, causing variable valve tenting. Combination of annular enlargement and valve tenting yields a variable degree of $\mathrm{TR}^{22}$ physiologically and pathologically. ${ }^{23}$ However, despite the considerable spectrum of causes of TR, ${ }^{24}$ annular enlargement plays a considerable role in FTR, much more than in functional MR, ${ }^{25}$ due to the specific disposition of the tricuspid subvalvular apparatus, which allows leaflet separation that can be considerable. ${ }^{23}$ While for any given annular dilatation TR varies according to the leaflet coverage, even patients with strictly normal leaflets, normal pulmonary pressure, and normal left ventricular function may display massive TR due to pure annular dilatation, ${ }^{26}$ which adversely affects outcome. ${ }^{27}$ Thus, while annuloplasty has been judged often insufficient in treating functional MR, ${ }^{28} \mathrm{TA}$ remains an essential tool in treating and preventing TR. ${ }^{12}$ While annular dilatation contribution to TR is well recognized, ${ }^{22}$ the causal mechanisms of annular enlargement remain incompletely defined. Previous studies have emphasized the link between atrial fibrillation and tricuspid annular enlargement, which was also confirmed in our study, and is probably a consequence of right atrial enlargement in the context of AFib secondarily affecting the tenuous tricuspid annulus, potentially leading to severe TR. ${ }^{23,27,29}$ AFib association with more severe FTR is found in many conditions, ${ }^{27,30}$ particularly with DMR, ${ }^{4}$ and its presence should attract attention toward FTR presence or tricuspid annulus enlargement. However, tricuspid annulus dilatation does not just occur in AFib but also in sinus rhythm, and deliberate measurement of tricuspid annulus dimensions should be the rule in patients with DMR. ${ }^{15}$ In this context, what should be the appropriate 


\section{GUIDELINE-BASED FUNCTIONNAL TRICUSPID} REGURGITATION SURGERY IN DMR
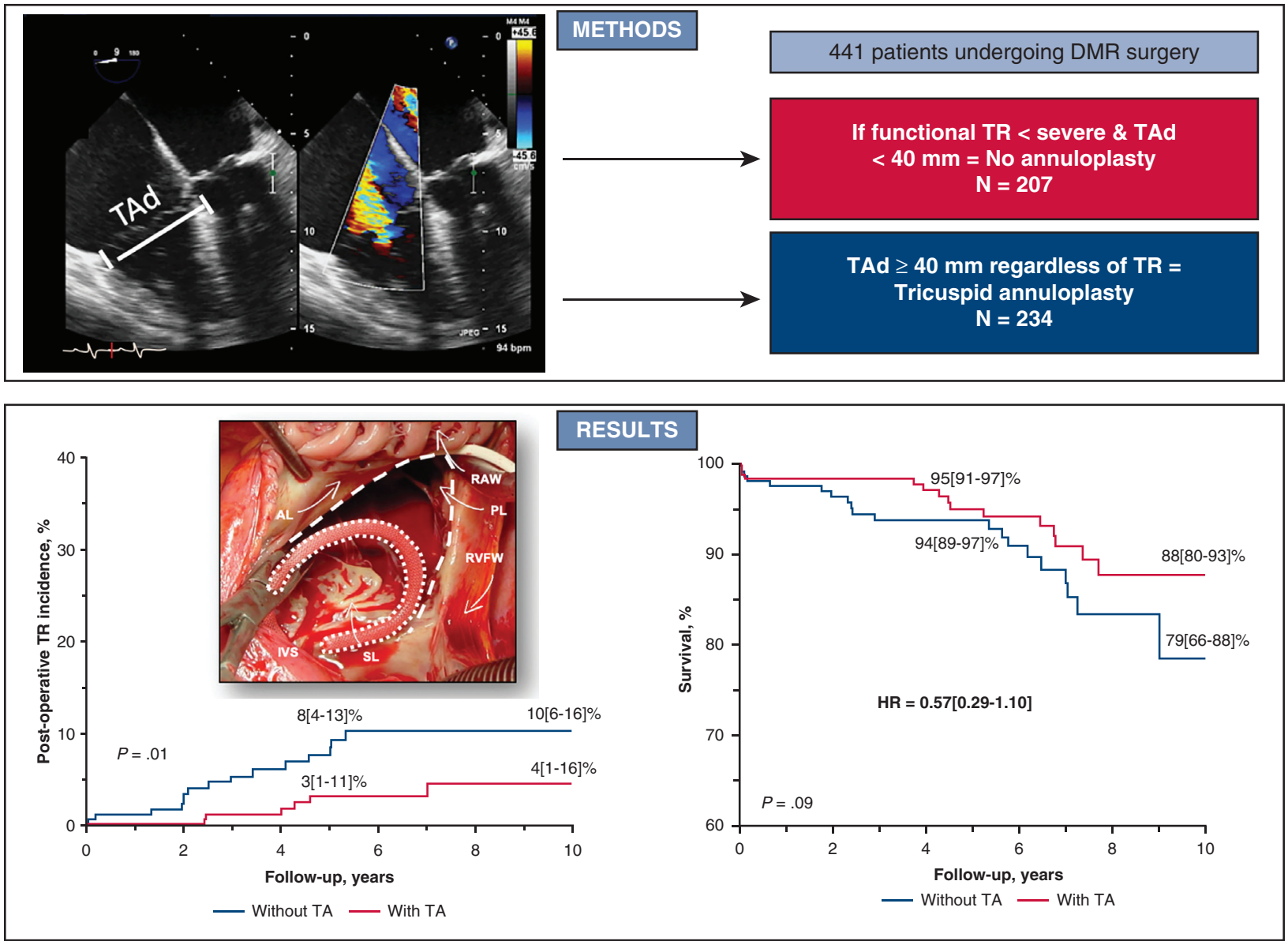

\section{IMPLICATION}

A safe and effective approach underscoring the potential for patients $\mathrm{TAd}<40 \mathrm{~mm}$ to require annuloplasty $\&$ the need for prospective studies to determine the most appropriate threshold for this indication.

FIGURE 4. Outcome of guideline-based functional TR surgery in DMR. Top, Methods. Inclusion of 441 undergoing DMR surgery with (left) echocardiographic preoperative assessment of functional TR severity and (right) stratified by TAd receive concomitant guideline-based tricuspid annuloplasty. Middle, Results. Long-term survival (left) stratified by TA, with a trend for greater survival in patients with TA (blue curve). Top right, Intraoperative view of TA sizing with native tricuspid annulus (dashed line) and Carpentier-Edwards ring (dotted line). Bottom right, Impact of TA on postoperative FTR, with significant lower FTR long-term in DMR-operated patients receiving concomitant TA based on guidelines (blue curve). Bottom, Implications for clinical care and future research. $D M R$, Degenerative mitral regurgitation; $T R$, tricuspid regurgitation; $T A d$, tricuspid annular diameter; $T A$, tricuspid annuloplasty; $H R$, hazard ratio.

annular dimension threshold guiding interventions? Our own intraoperative observations of 2005 , referring to a population operated from 1989 to $2001,{ }^{6}$ were linked to the echocardiographic annular dimension of $40 \mathrm{~mm},{ }^{15}$ whereas others suggested use of annular dimension normalized to body-surface area $\left(21 \mathrm{~mm} / \mathrm{m}^{2}\right){ }^{31}$

Although mentioned by guidelines, ${ }^{15,16}$ current thresholds are approximative, while persistence of notable TR incidence in patients without TA, linked to their baseline annulus diameters in the present series, suggests that the most effective threshold for tricuspid repair may be $<40 \mathrm{~mm}$. Irrespective, discrepant observations on annular enlargement ${ }^{10,14}$ suggest that large multicenter cohorts are warranted to examine optimal thresholds based on outcome data to improve FTR management. 


\section{Management of the Tricuspid Valve in DMR}

TR is profoundly undertreated, with fewer than 10,000 cases operated yearly of the 160,000 to 240,000 incident cases estimated to occur in the United States. ${ }^{32}$ This observation is particularly relevant because the "benign" outcome of TR has been proven untrue overall ${ }^{33}$ and in each specific clinical context examined. ${ }^{1,27,30}$ Cohorts focused on the importance of FTR in DMR are rare, but recent data suggest that FTR, even moderate, has a considerable impact on longterm mortality, particularly under medical management but continues to affect survival even after successful mitral surgery. ${ }^{4}$ This considerable mortality is coupled with a marked undertreatment, ${ }^{4}$ particularly striking in this highly surgical context. Because reoperation for TR is associated with high operative mortality and suboptimal outcomes, ${ }^{34,35}$ it is essential to optimize the treatment/prevention of FTR in patients with DMR. Our cohort, unique by its size and its dense and prolonged echocardiographic follow-up (Figures E1E6) shows that the application of a guideline-based approach, involving consistent application of class I and IIa indications to the tricuspid valve management, markedly increases the frequency with which TA is performed (vs only class I indications), increases the bypass time, but does not result in any increase in short- and long-term mortality or complications of the DMR surgery. Furthermore, our unique long-term follow-up shows a considerable benefit of TA performance versus no tricuspid intervention in a lower incidence of late moderate or severe FTR. Hence, this approach is not only safe but effective. We believe that these outcome observations should reassure practitioners and lead to more consistent application of tricuspid guidelines within the context of DMR. Recurrent FTR is often delayed postmitral repair, and our series also emphasizes the importance of regular Doppler-echocardiographic follow-up in the decades following the surgery.

\section{Limitations}

Although we retrospectively identified patients, TAd measurements, FTR assessment, and all echocardiographic and surgical data were prospectively collected, stored immediately postmeasurement, and retrieved electronically without modification. This study involved patients from 2 different centers but operated on by the cardiac team with a uniform standard of care. Echocardiographic measurements were not read by a core laboratory but were uniformly interpreted. Even though tricuspid annular diameter measurement was not part of routine assessment, all echocardiographic preoperative assessment of patients referred to the cardiac team for mitral valve surgery had TAd measurement, thus alleviating the bias of excluded patients without TA dilatation, less likely to have TAd measured on a routine. The choice of a 40-mm cut-off for TAd was a priori based on our previous experience supported by guidelines but does not allow to define the optimal annular threshold to perform TA. Data extraction was limited to patients fulfilling our cohort's criteria but our study addresses for the first time the outcome following strict application of guideline-based FTR surgery. Finally, one weakness of all tricuspid valve studies is the lack of consistent right ventricular function measure, which was not been available throughout the study period. Future cohorts of DMR analyzing TAd importance in clinical decision-making should include AFib ablation outcome and quantitative/consistent measure of $\mathrm{RV}$ function to assess whether those provide a modulation for the performance of TA in the context of DMR.

\section{CONCLUSIONS}

Our consecutive series of patients undergoing surgery for DMR with uniform guideline-based tricuspid management involving TA performed in patients with severe TR preoperatively (class I) or any degree of TR and tricuspid annulus dimension $\geq 40 \mathrm{~mm}$ (Class IIa) demonstrates that this approach is safe and effective. It results in a low rate of long-term postoperative moderate or severe FTR with no increase in hospital mortality or morbidity in patients requiring TA. Patients who did not receive TA, despite a lower tricuspid annular dimension, incurred a higher postoperative TR incidence than patients who underwent annuloplasty, emphasizing the long-term protective impact of the annuloplasty ring implantation. This greater rate, powerfully determined by the tricuspid annular dimension at baseline, underscores the potential for patients with annular diameters $<40 \mathrm{~mm}$ to require annuloplasty and the need for prospective studies to determine the most appropriate threshold for this indication. Thus, our consistent experience with proactive tricuspid repair during DMR repair, while considerably increasing the number of tricuspid repairs performed versus a policy based on presence of severe TR alone, did not increase the risks incurred by patients and reduced the rates of recurrent TR long term after surgery.

\section{Conflict of Interest Statement}

Dr Dreyfus reports speaker fees from Edwards Lifesciences. Dr Enriquez-Sarano received consulting fees from Edwards LLC, CryoLife Inc, and Mardil, Inc. All other authors reported no conflicts of interest.

The Journal policy requires editors and reviewers to disclose conflicts of interest and to decline handling or reviewing manuscripts for which they may have a conflict of interest. The editors and reviewers of this article have no conflicts of interest.

\section{References}

1. Topilsky Y, Maltais S, Medina Inojosa J, Oguz D, Michelena H, Maalouf J, et al Burden of tricuspid regurgitation in patients diagnosed in the community Setting. JACC Cardiovasc Imaging. 2019;12:433-42. 
2. Dziadzko V, Dziadzko M, Medina-Inojosa JR, Benfari G, Michelena HI, Crestanello JA, et al. Causes and mechanisms of isolated mitral regurgitation in the community: clinical context and outcome. Eur Heart J. 2019;40:2194-202.

3. Varadarajan P, Pai RG. Tricuspid regurgitation in patients with severe mitral regurgitation and normal left ventricular ejection fraction: risk factors and prognostic implications in a cohort of 895 patients. J Heart Valve Dis. 2010;19:412-9.

4. Essayagh B, Antoine C, Benfari G, Maalouf J, Michelena HI, Crestanello JA, et al. Functional tricuspid regurgitation of degenerative mitral valve disease: a crucial determinant of survival. Eur Heart J. 2020;41:1918-29.

5. Goldstone AB, Howard JL, Cohen JE, MacArthur JW Jr, Atluri P, Kirkpatrick JN, et al. Natural history of coexistent tricuspid regurgitation in patients with degenerative mitral valve disease: implications for future guidelines. J Thorac Cardiovasc Surg. 2014;148:2802-9.

6. Dreyfus GD, Corbi PJ, Chan KM, Bahrami T. Secondary tricuspid regurgitation or dilatation: which should be the criteria for surgical repair? Ann Thorac Surg. 2005;79:127-32.

7. McCarthy PM, Bhudia SK, Rajeswaran J, Hoercher KJ, Lytle BW, Cosgrove DM, et al. Tricuspid valve repair: durability and risk factors for failure. J Thorac Cardiovasc Surg. 2004;127:674-85.

8. De Bonis M, Alfieri O, Dalrymple-Hay M, Del Forno B, Dulguerov F, Dreyfus G. Mitral valve repair in degenerative mitral regurgitation: state of the art. Prog Cardiovasc Dis. 2017;60:386-93.

9. Suri RM, Vanoverschelde JL, Grigioni F, Schaff HV, Tribouilloy C, Avierinos JF, et al. Association between early surgical intervention vs watchful waiting and outcomes for mitral regurgitation due to flail mitral valve leaflets. JAMA. 2013;310:609-16.

10. Chikwe J, Itagaki S, Anyanwu A, Adams DH. Impact of concomitant tricuspid annuloplasty on tricuspid regurgitation, right ventricular function, and pulmonary artery hypertension after repair of mitral valve prolapse. J Am Coll Cardiol. 2015;65:1931-8.

11. Benedetto U, Melina G, Angeloni E, Refice S, Roscitano A, Comito C, et al. Prophylactic tricuspid annuloplasty in patients with dilated tricuspid annulus undergoing mitral valve surgery. J Thorac Cardiovasc Surg. 2012;143:632-8.

12. Rogers JH, Bolling SF. The tricuspid valve: current perspective and evolving management of tricuspid regurgitation. Circulation. 2009;119:2718-25.

13. Yilmaz O, Suri RM, Dearani JA, Sundt TM III, Daly RC, Burkhart HM, et al. Functional tricuspid regurgitation at the time of mitral valve repair for degenerative leaflet prolapse: the case for a selective approach. J Thorac Cardiovasc Surg. 2011;142:608-13.

14. David TE, David CM, Manlhiot C. Tricuspid annulus diameter does not predict the development of tricuspid regurgitation after mitral valve repair for mitral regurgitation due to degenerative diseases. J Thorac Cardiovasc Surg. 2018; $155: 2429-36$.

15. Baumgartner H, Falk V, Bax JJ, De Bonis M, Hamm C, Holm PJ, et al. 2017 ESC/ EACTS Guidelines for the management of valvular heart disease. Eur Heart J. 2017;38:2739-91.

16. Nishimura RA, Otto CM, Bonow RO, Carabello BA, Erwin JP III, Guyton RA, et al. 2014 AHA/ACC guideline for the management of patients with valvular heart disease: a report of the American College of Cardiology/American Heart Association task force on practice guidelines. J Thorac Cardiovasc Surg. 2014; 148:e1-132.

17. Zoghbi WA, Enriquez-Sarano M, Foster E, Grayburn PA, Kraft CD, Levine RA, et al. Evaluation of the severity of native valvular regurgitation with twodimensional and Doppler echocardiography: a report from the task force on valvular regurgitation of the American Society of Echocardiography. J Am Soc Echocardiogr. 2003; 16:777-802.

18. Antoine C, Mantovani F, Benfari G, Mankad SV, Maalouf JF, Michelena HI, et al Pathophysiology of degenerative mitral regurgitation: new 3-dimensional imaging insights. Circ Cardiovasc Imaging. 2018;11:e005971.

19. Antoine C, Benfari G, Michelena HI, Maalouf JF, Nkomo VT, Thapa P, et al. Clinical Outcome of degenerative mitral regurgitation: critical importance of echocardiographic quantitative assessment in routine practice. Circulation. 2018;138:1317-26.

20. Lang RM, Bierig M, Devereux RB, Flachskampf FA, Foster E, Pellikka PA, et al. Recommendations for chamber quantification: a report from the American Society of Echocardiography's guidelines and Standards Committee and the Chamber Quantification Writing Group, developed in conjunction with the European Association of Echocardiography, a branch of the European Society of Cardiology. J Am Soc Echocardiogr. 2005;18:1440-63.

21. Topilsky Y, Tribouilloy C, Michelena HI, Pislaru S, Mahoney DW, EnriquezSarano M. Pathophysiology of tricuspid regurgitation: quantitative Doppler echocardiographic assessment of respiratory dependence. Circulation. 2010; 122:1505-13.

22. Badano LP, Muraru D, Enriquez-Sarano M. Assessment of functional tricuspid regurgitation. Eur Heart J. 2013;34:1875-85.

23. Topilsky Y, Khanna A, Le Tourneau T, Park S, Michelena H, Suri R, et al. Clinical context and mechanism of functional tricuspid regurgitation in patients with and without pulmonary hypertension. Circ Cardiovasc Imaging. 2012;5:314-23.

24. Prihadi EA, van der Bijl P, Dietz M, Abou R, Vollema EM, Marsan NA, et al. Prognostic implications of right ventricular free wall longitudinal strain in patients with significant functional tricuspid regurgitation. Circ Cardiovasc Imaging. 2019;12:e008666.

25. Yiu SF, Enriquez-Sarano M, Tribouilloy C, Seward JB, Tajik AJ. Determinants of the degree of functional mitral regurgitation in patients with systolic left ventricular dysfunction: a quantitative clinical study. Circulation. 2000; 102:1400-6.

26. Utsunomiya H, Itabashi Y, Mihara H, Berdejo J, Kobayashi S, Siegel RJ, et al. Functional tricuspid regurgitation caused by chronic atrial fibrillation: a realtime 3-dimensional transesophageal echocardiography study. Circ Cardiovasc Imaging. 2017; 10:e004897.

27. Topilsky Y, Nkomo VT, Vatury O, Michelena HI, Letourneau T, Suri RM, et al. Clinical outcome of isolated tricuspid regurgitation. JACC Cardiovasc Imaging. 2014;7:1185-94.

28. Acker MA, Parides MK, Perrault LP, Moskowitz AJ, Gelijns AC, Voisine P, et al. CTSN. Mitral-valve repair versus replacement for severe ischemic mitral regurgitation. N Engl J Med. 2014;370:23-32.

29. Yamasaki N, Kondo F, Kubo T, Okawa M, Matsumura Y, Kitaoka H, et al. Severe tricuspid regurgitation in the aged: atrial remodeling associated with longstanding atrial fibrillation. J Cardiol. 2006;48:315-23.

30. Benfari G, Antoine C, Miller WL, Thapa P, Topilsky Y, Rossi A, et al. Excess mortality associated with functional tricuspid regurgitation complicating heart failure with reduced ejection fraction. Circulation. 2019;140:196-206.

31. Colombo T, Russo C, Ciliberto GR, Lanfranconi M, Bruschi G, Agati S, et al. Tricuspid regurgitation secondary to mitral valve disease: tricuspid annulus function as guide to tricuspid valve repair. Cardiovasc Surg. 2001;9:369-77.

32. Enriquez-Sarano M, Messika-Zeitoun D, Topilsky Y, Tribouilloy C, Benfari G, Michelena H. Tricuspid regurgitation is a public health crisis. Prog Cardiovasc Dis. 2019;62:447-51.

33. Nath J, Foster E, Heidenreich PA. Impact of tricuspid regurgitation on long-term survival. J Am Coll Cardiol. 2004;43:405-9.

34. King RM, Schaff HV, Danielson GK, Gersh BJ, Orszulak TA, Piehler JM, et al. Surgery for tricuspid regurgitation late after mitral valve replacement. Circulation. 1984;70:I193-7.

35. Kilic A, Saha-Chaudhuri P, Rankin JS, Conte JV. Trends and outcomes of tricuspid valve surgery in North America: an analysis of more than 50,000 patients from the Society of Thoracic Surgeons database. Ann Thorac Surg. 2013;96:1546-52; discussion 1552.

Key Words: tricuspid regurgitation, ACC/AHA guidelines, mitral valve repair, tricuspid annular diameter 

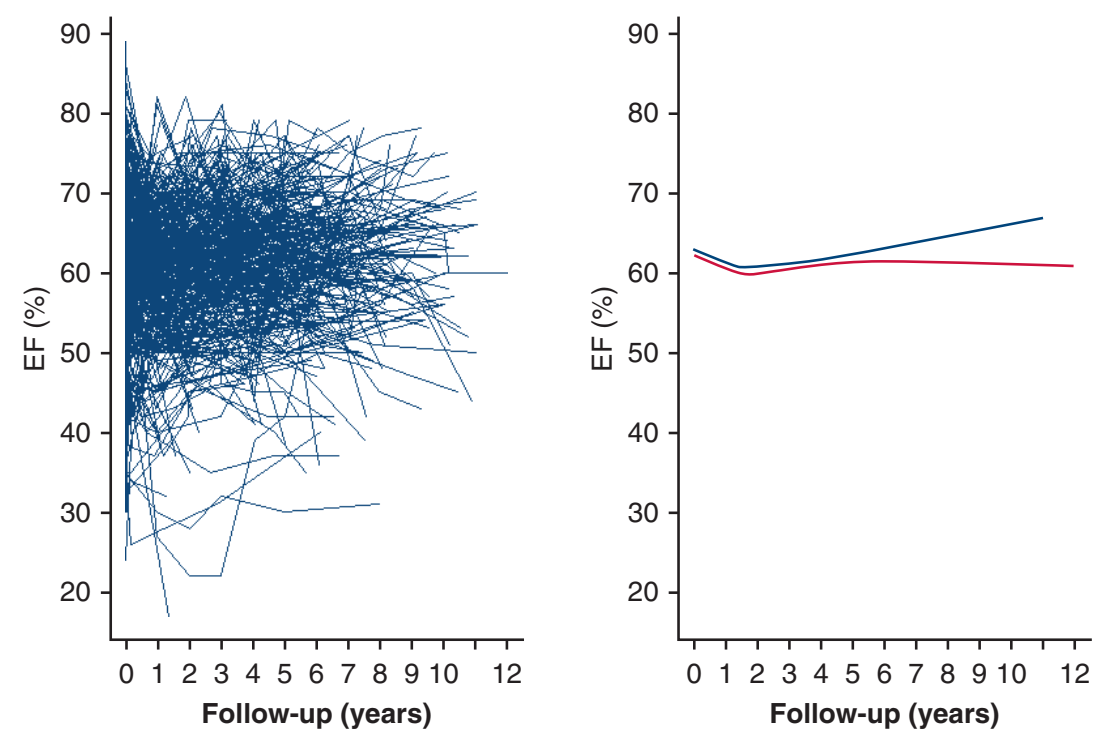

- Without TA - With TA

FIGURE E1. Individual evolutions (left) and smoothed average evolution (right) of ejection fraction (LV-EF, \%) during follow-up of patients with TA and without TA. $E F$, Ejection fraction; TA, tricuspid annuloplasty.
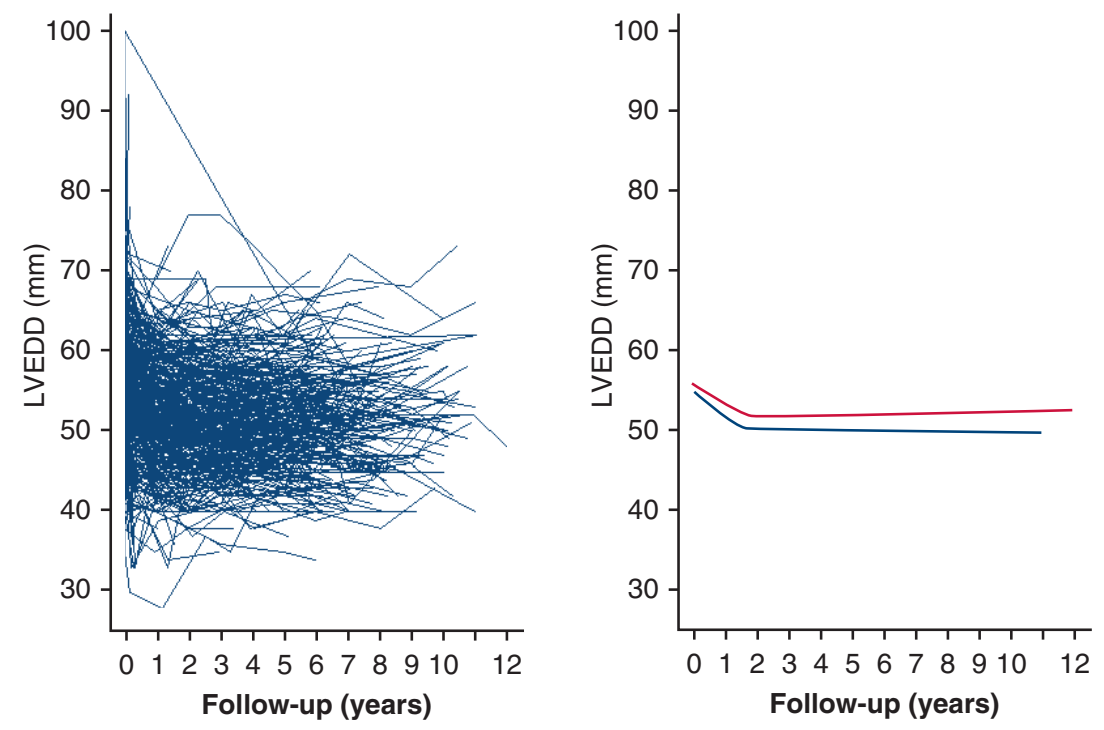

- Without TA - With TA

FIGURE E2. Individual evolutions (left) and smoothed average evolution (right) of LV-EDD (mm) during follow-up of patients with TA and without TA. $L V$-EDD, Left ventricle end-diastolic diameter; $T A$, tricuspid annuloplasty. 

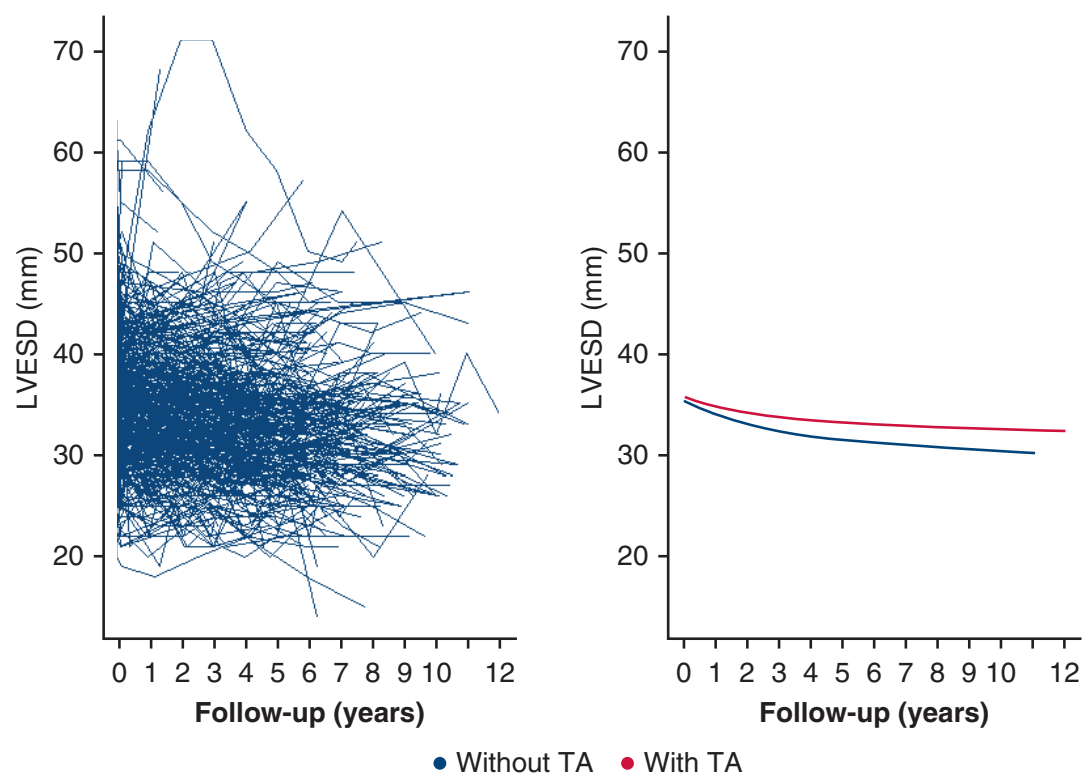

FIGURE E3. Individual evolutions (left) and smoothed average evolution (right) of LV-ESD (mm) during follow-up of patients with TA and without TA. $L V$-ESD, Left ventricle end-systolic diameter; $T A$, tricuspid annuloplasty.
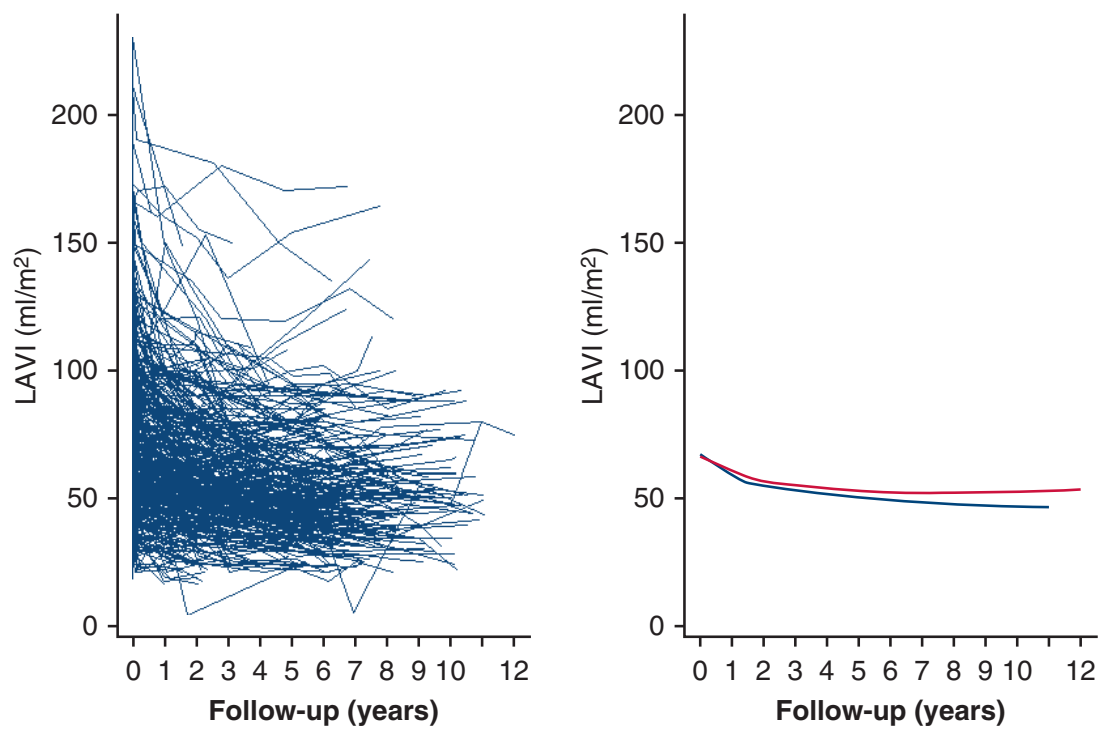

- Without TA - With TA

FIGURE E4. Individual evolutions (left) and smoothed average evolution (right) of LAVI ( $\left.\mathrm{mL} / \mathrm{m}^{2}\right)$ during follow-up of patients with TA and without TA. $L A V I$, Left atrial volume index; TA, tricuspid annuloplasty. 

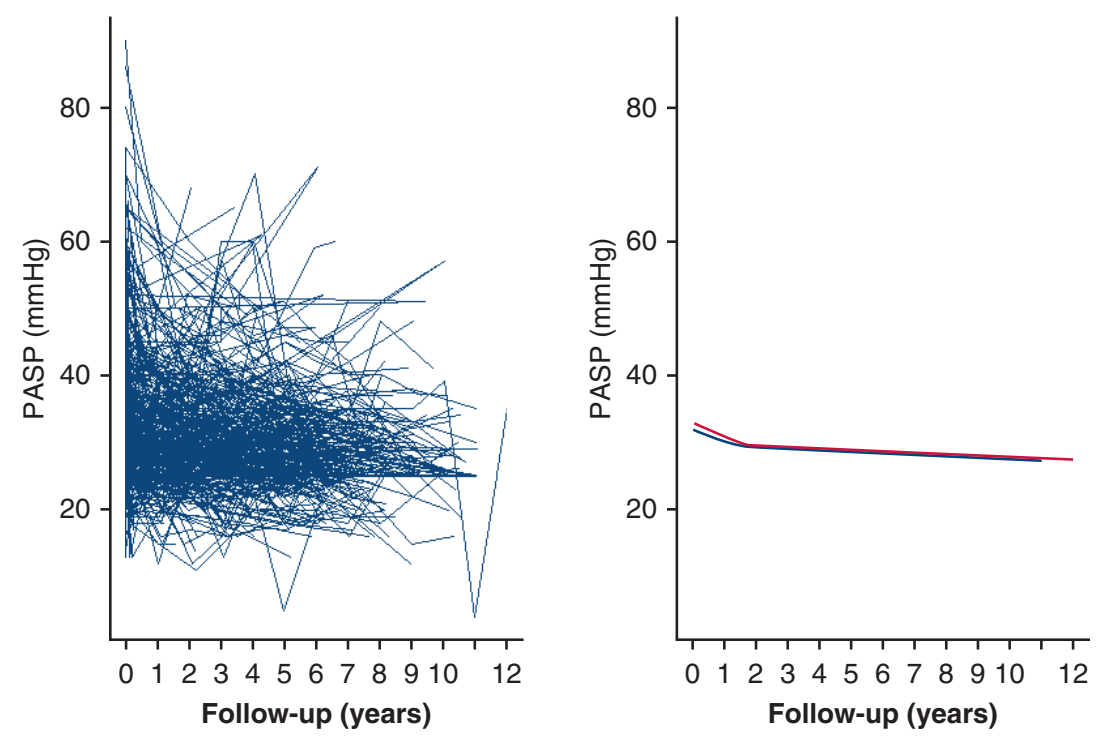

- Without TA - With TA

FIGURE E5. Individual evolutions (left) and smoothed average evolution (right) of sPAP (mm Hg) during follow-up of patients with TA and without TA $s P A P$, Systolic pulmonary artery pressure; $T A$, tricuspid annuloplasty.
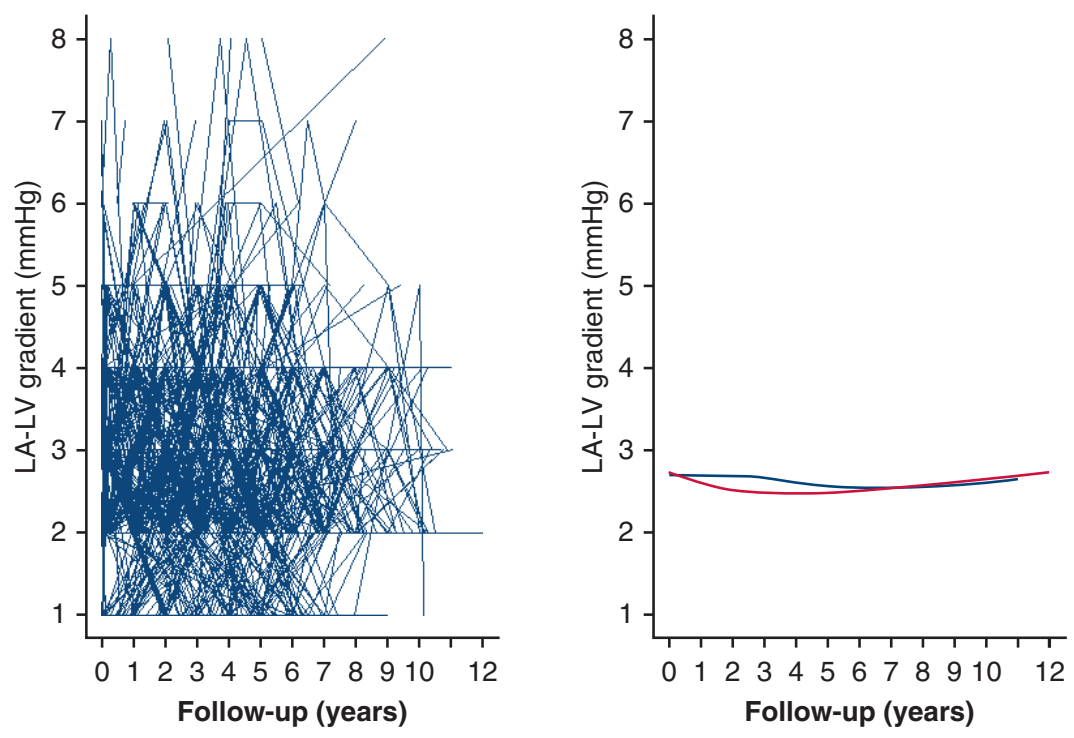

- Without TA • With TA

FIGURE E6. Individual evolutions (left) and smoothed average evolution (right) of LA-LV gradient (mm Hg) during follow-up of patients with TA and without TA. $L A$, Left atrium; $L V$, left ventricle; $T A$, tricuspid annuloplasty. 
TABLE E1. Longitudinal echocardiographic data modeled by linear mixed-effects models in the overall cohort

\begin{tabular}{lccccc}
\hline \multicolumn{1}{c}{ Parameter } & Intercept & Linear time effect $(\mathbf{t})$ & $\begin{array}{c}\text { Quadratic time } \\
\text { effect }\left(\mathbf{t}^{\mathbf{2}}\right) \times \mathbf{1 0}^{-\mathbf{2}}\end{array}$ & TA effect intercept & TA effect interaction \\
\hline LV-EF, \% & 62.1 & $-0.083 \pm 0.019^{*}$ & $0.099 \pm 0.021^{*}$ & $P=.09$ & $P=.03$ \\
& 60.9 & $-0.026 \pm 0.017$ & $0.020 \pm 0.017$ & $P=.003$ \\
\hline LV-EDD, mm & 54.4 & $-0.15 \pm 0.013^{*}$ & $0.11 \pm 0.014^{*}$ & $P=.005$ & $P=.6$ \\
& 56.0 & $-0.16 \pm 0.011^{*}$ & $0.11 \pm 0.011^{*}$ & $P=.8$ \\
\hline LV-ESD, mm & 35.5 & $-0.091 \pm 0.011^{*}$ & $0.046 \pm 0.012^{*}$ & $P=.1$ & $P=.2$ \\
\hline LAVI, mL/m 2 & 36.3 & $-0.070 \pm 0.010^{*}$ & $0.032 \pm 0.010^{*}$ & & $P=.4$ \\
& 74.8 & $-0.78 \pm 0.045^{*}$ & $0.52 \pm 0.048^{*}$ & $P=.7$ & $P=.02$ \\
\hline sPAP, mm Hg & 75.8 & $-0.63 \pm 0.040^{*}$ & $0.39 \pm 0.040^{*}$ & & $P=.045$ \\
\hline LA-LV gradient, mm Hg & 34.8 & $-0.15 \pm 0.020^{*}$ & $0.068 \pm 0.021^{*}$ & $P=.3$ & $P=.09$ \\
\hline NYHA III/IV & 35.7 & $-0.19 \pm 0.016^{*}$ & $0.10 \pm 0.016^{*}$ & & $P=.2$ \\
\hline MR $>$ 2+ & 2.82 & $-0.0018 \pm 0.0030$ & $0.0003 \pm 0.0030$ & $P=.4$ & $P=1$ \\
\hline
\end{tabular}

For each parameter, the first line corresponds to patients without TA (light blue) and the second line to patients with TA (dark blue). TA, Tricuspid annuloplasty; $L V$, left ventricle; $E F$, ejection fraction; $E D D$, end-diastolic diameter; $E S D$, end-systolic diameter; $L A V I$, left atrial volume index; $s P A P$, systolic pulmonary artery pressure; $L A$, left atrium; $N Y H A$, New York Heart Association functional classification; $M R$, mitral regurgitation. *Statistically significant $(P<.0001)$. 